\title{
The influence of environment, predisposing, enabling and need variables on personal health choices of adults with intellectual disability
}

\author{
Philip McCallion $^{1^{*}}$, Eilish Burke ${ }^{2}$, Janet Swinburne ${ }^{2}$, Eimear McGlinchey ${ }^{2}$, Rachael Carroll ${ }^{2}$, \\ Mary McCarron ${ }^{2}$ \\ ${ }^{1}$ Center for Excellence in Aging and Community Wellness, University at Albany, Albany, USA; \\ *Corresponding Author: mcclion@albany.edu \\ ${ }^{2}$ School of Nursing \& Midwifery, Trinity College, Dublin, Ireland
}

Received 15 February 2013; revised 21 March 2013; accepted 6 April 2013

Copyright (C) 2013 Philip McCallion et al. This is an open access article distributed under the Creative Commons Attribution License, which permits unrestricted use, distribution, and reproduction in any medium, provided the original work is properly cited.

\section{ABSTRACT}

Attention to disease and risk factor management is increasingly a feature of people with intellectual disability (ID) as an augmented life expectancy also exposes a growing number of agerelated diseases. An additional concern is little attention to date to physical activity, nutrition, access to social support and other personal health choices and to environmental issues such as the impact of access to social support and the implications of individual's living arrangements. Method: Using a sample of 753 persons with ID from the intellectual disability supplement to the Irish longitudinal study on ageing (IDS-TILDA), forty three variables were grouped into environmental, predisposing, enabling, need and personal health choices clusters and hierarchical ordinary least squares regression examined the contribution of environmental, enabling, predisposing, need and all combinations of the sets of variables to personal health choices. Findings: Almost $32 \%$ of variance was explained primarily by need variables. Most significant relationships were with meeting up with family and friends (environmental), age, rating of health and worries about getting older (predisposing), having public health insurance and nursing who come into the home (enabling) and presence of stroke, chronic constipation, functional limitations, high assistance needs with activities of daily living (need). Discussion: Taken together, the groupings of variables from the Anderson Model explained a modest amount of variance in the pursuit of positive personal health choices by people with ID. More work is clearly needed in developing evidence-based interventions and strategies, and in understanding the relationship between positive personal health choices of people with ID and health outcomes.

Keywords: Personal Health Choices; Intellectual Disability; Chronic Conditions

\section{INTRODUCTION}

Estimates suggest that life expectancy for people with an intellectual disability (ID) have increased from an average 18 years in 1930 , to 59 years in 1970 , to 66 years in 1993, with projected continued growth to eventually match life expectancy of the general population [1]. By 2020 the number of persons with ID aged over 65 is therefore projected to double from 1990 estimates [2]. However, it remains to be definitively established whether for most older adults with ID those extended years are healthy or unhealthy [3].

Attention to disease and risk factor management is increasingly a feature of people with ID as an augmented life expectancy also exposes a growing number of persons with ID to age-related diseases. An additional concern is little attention to date to physical activity, nutriation, access to social support and other personal health choices demonstrated to improve longevity [4,5] and to environmental issues such as the impact of access to social support and the implications of individual's living arrangements [6-8].

Available data raises that individuals with ID have a greater variety of health care needs compared to those of the same age and gender in the general population [9, 
10]; people with ID have 2.5 times the health problems of those without ID [11]; rates of psychopathology are considerably higher in individuals with ID compared to the general population [12]; obesity as measured by BMI is reported to be highly prevalent $[13,14]$; people with ID are more likely to lead unhealthy lifestyles contributing to the development of physical ailments in later life [3,15, 16]; health problems of persons with intellectual disability are not being recognized [17]; poor health and early mortality among people with ID may be related to the location and types of health care services people with ID have received over a life time as well as in their older years [18]; there is a lack of specialist knowledge and training on health and aging issues for people with ID [19]; and people with ID do not access health promotion and health screening services to the same extent as peers without disability [20].

There are additional concerns that people with lifelong disabilities also often experience secondary health conditions such as decubitus ulcers and urinary tract infections at higher rates than the general population [21] and that the consequences of additional health concerns as they age often have a greater impact on the independence and quality of life of people with ID suggesting that proactive health promoting steps including personal health choices are particularly pertinent [22].

Lack of health education and health awareness has also been noted as presenting an additional barrier to health promoting practices among people with disabilities [23]; as has difficulties in accessing and in participating in personal health choices such as regular physical activity, good nutrition, and completing preventive screenings [24]; and living circumstances that may promote inactivity and poor lifestyle choices [25]. Yet there is data that suggests that people with ID do benefit from targeted health promotion and screening programs $[24,26$, 27].
Improvements are called for in our understanding of the health of people with ID as they age as well as the factors that are likely to promote or prevent health promotion including personal health choices. To begin to identify those factors it was decided to use a modified version of the Anderson Behavioral Model [28] as the conceptual framework to predict personal health choices. The model groups variables into environmental, population characteristics (predisposing characteristics, enabling resources and need) and personal health choices. The full Anderson model also considers the role of the health care system under environment and use of health services under health behavior but these aspects of the model were not included here to more fully explore the role of where people live and of population characteristics on personal health choices (Figure 1).

\section{METHOD}

Data for this analysis was drawn from the first wave of data collected as a part of the Intellectual Disability Supplement to the Irish Longitudinal Study on Ageing (IDSTILDA). IDS-TILDA is a multi-wave longitudinal study of older adults with ID designed to explore their ageing profile, physical and behavioral health, health service needs, psychological health, social networks, living situations, community participation and employment [14].

Sample: The sample was randomly selected from Ireland's National Intellectual Disability Database (NIDD) which collects information on 26,000 people registered with all levels of ID and in a full range of residential circumstances, eligible for or receiving services [29]. The inclusion criteria were: age $\geq 40$ years with intellectual disability and written consent to participate and/or family/guardian written agreement, where required. Age 40 years were selected to reflect the lower longevity of people with ID to ensure that there would be sufficient

The Anderson Model of Health Cara Utilization

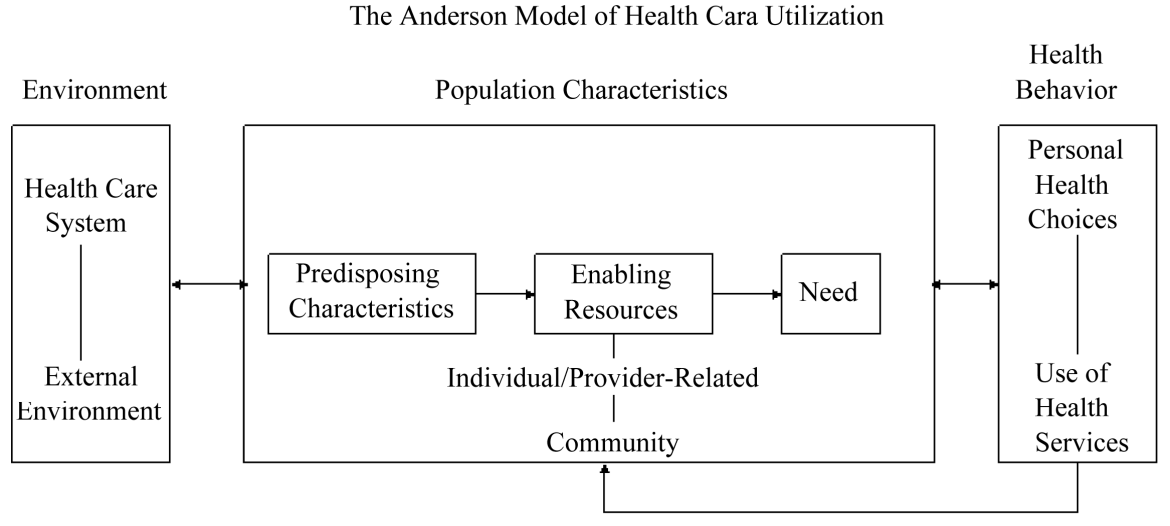

RM Anderson. Revisiting the behavioral model and access to medical care: does it matter? J Health Social Behavior 1995;36:1110

Figure 1. The Anderson model of health care utilization. 
subjects for future waves of data collection and because this would provide opportunities to offer insight into ageing for those who may age prematurely. The recruited, consented and protocols completed sample was 753 persons with an ID, aged between 41 and 90 years; an overall response rate of $46 \%$ comprising persons who represented $8.9 \%$ of the total population aged 40 and over registered on the 2008 NIDD database and upon further investigation were found to be representative of the larger population in terms of key demographics, geographic spread and living situations.

Anderson Model Variables: A total of 43 variables were included in the model. Given a sample size of 753 there are sufficient subjects to meet recommendations [10 subjects per variable) to ensure that there is sufficient power to find a significant relationship between independent and dependent variables [30]. Most variables in the IDSTILDA are similar to those used in the larger The Irish Longitudinal Study on Ageing [32] where data was being collected during the same time period in order to maximize the opportunities to compare the health, life experiences and ageing of people with ID with their adult peers in Ireland (see [14] for more detail on the study and on the interview protocols). Consistent with Anderson [28], the variables were grouped as follows:

Environment variables included: availability of inhome support from spouse and/or children (yes/no); type of residence (scaled from independent to residential living); whether the place lived in had all facilities on the same floor/level (yes/no); whether the person had difficulty navigating the place where they lived (yes/no); and how often they met up with family/friends (summed score of encounters).

Predisposing variables included: gender; age; level of intellectual disability; concerns or worries about getting old (yes/no); feel lonely (yes/no); extent feel happy (scaled); and self-rated health (scaled).

Enabling variables included: impact of lack of transportation on lifestyle; availability of both public and private medical coverage; support from nursing staff in the home (yes/no); support from other staff at home (yes/no); number of health screens/tests completed in last 12 months; and the level of access to "easy-read" health materials (summed score).

Need variables included: reports for each of the fourteen most common health conditions (yes/no), a summed memory score drawn from the TSI instrument completed by the interviewer [31]; functional limitations (total score); activities of daily living support needs (total score); instrumental activities of daily living support needs (total score); and perceived weight concerns (scaled).

Personal Health Choices variables included: Cigarette use and alcohol consumption (summed score); regular moderate or vigorous physical activity (yes/no); trouble falling asleep (yes/no); number of social activities engaged in; and how many servings of fruit and vegetables are eaten daily.

Ethical Approval. The IDS-TILDA study received ethics approval from the Faculty of Health Sciences Ethics Committee at Trinity College Dublin and all of the participating services providers $(N=138)$.

Analysis: Hierarchical ordinary least squares regression analyses were used to analyze the data. The model developed for Personal Health Choice examined the contribution of environmental, enabling, predisposing, need and all combinations of the sets of variables were analyzed. Unstandardized beta coefficients were estimated at the final step of the hierarchical ordinary least squares regression. The normality of the residuals from the regression model was checked; no variables had to be transformed. The regression model was also checked in initial diagnostic data runs for problems with collinearity and heteroscedasticity and no problems were found.

\section{FINDINGS}

Of the 753 subjects, $45 \%$ were male and $55 \%$ female. The mean age of the group was 54.75 years $(\mathrm{SD}=9.56)$ with $36 \%$ aged 40 - 49 years; $46 \%$ aged $50-64$ years and $18 \%$ aged 65 years and over. Overall, 24\% were classified as having a mild ID, $46 \%$ a moderate ID, $24 \%$ a severe ID, $5 \%$ a profound ID and $5 \%$ were ID unverified. Those with an unverified level of ID were excluded from subsequent analyses. Two fifths (40.2\%) lived in a 52 week residential centre, while a further $5.3 \%$ lived either in a five day a week residential centre or a residential centre that involved two weeks or more holidays (vacation) per year. One third (34.1\%) lived in community group homes. Five percent lived independently or semi-independently and the remaining $11 \%$ lived at home, supported by their families. Of the family supported group, 32 resided with a sibling or other relative and 51 lived with one or both parents.

Health status: Approximately $12 \%$ of participants rated their health as excellent, $36 \%$ as very good, $37 \%$ as good, $11 \%$ as fair, while $4 \%$ described their health as poor. The number of chronic conditions reported ranged as high as seven with a median of two conditions and $71 \%$ were multi morbid (i.e. having two or more chronic conditions). For men and women, mental health concerns, eye disease, neurological disease and gastrointestinal concerns were the highest occurring conditions. Eye disease was significantly higher in women with ID as was joint disease and hypertension. Diseases in order of prevalence were: eye disease, mental health disease, neurological disease, gastrointestinal disease, endocrine disease, joint disease, hypertension, heart disease, lung dis- 
ease, cancer, stroke and liver disease and rates of disease increased with age.

One in three adults with ID (32\%) reported a doctor's diagnosis of high cholesterol and rates of hypertension rose to almost $27 \%$ for those over age 65 years. In terms of falls, $26.7 \%$ of adults with ID reported sustaining a fall in the past year and of those who fell, 7\% reported having had two or more falls; the rate of reported osteoporosis in the IDS-TILDA sample was $8.1 \%$.

Health care utilization: People with ID were found to access healthcare at a similar rate to the Irish general adult and older population [32]. The general practitioneror primary care physician was the most frequently accessed healthcare service; people with ID living in residential programs reported receiving healthcare services more frequently than those living in a community setting or independently/with family; and regardless of reported chronic illness and disability, older adults with ID were less likely to have a hospital admission than their peers in the Irish general adult and older population [32]. Polypharmacy (five or more medications or supplements) was present for $59 \%$ of the population and $91 \%$ reported taking at least one prescription or non-prescription medication.

Personal health choices: Sixty percent of respondents reported that they did not drink alcohol in the past 6 months and $50 \%$ of those who did, reported they had a drink once or twice a month or less. Prevalence of smoking was $8.1 \%$; this compares to $19 \%$ reported for the general Irish adult population [32]. Reported rates of physical activity were $80 \%$ engaged regularly in mild activity, $46 \%$ engaged; in moderate physical activity and $84.5 \%$ of respondents reported hardly ever doing vigorous physical activity.

Approximately 14\% rated their overall diet as nutritionally excellent, $50 \%$ as very good, $30 \%$ as good, $4 \%$ as fair, while $2 \%$ described their diet as poor. Approximately $1 \%$ reported having four or more servings of fruit or four or more servings of vegetables per day, $(69.8 \%$ reported between one and three servings of fruit and $87.6 \%$ between one and three servings of vegetables). Body Mass Index (BMI) scores, based on self-reported height and weight data $(N=584)$, revealed that $31 \%$ of participants scored in the obese category, 30\% fell into the overweight category, while $37 \%$ and $2 \%$ respectively, were in the normal and underweight category.

Table 1 presents data on the relative contribution of environmental, predisposing, enabling, and need variables to the overall model $\mathrm{R}^{2}$. As can be seen, need variables explained more variance in personal health choices than environmental, predisposing or enabling variables and that the addition of any of the other groupings of variables added little to the explained variance. Taken together the full model of independent variables ex-
Table 1. Model $\mathrm{R}^{2} \mathrm{~s}$ derived from the hierarchical regression of personal health choices on environment, predisposing, enabling, and need variables.

\begin{tabular}{lc}
\hline Variable & $\begin{array}{c}\text { Personal Health } \\
\text { Choices }\end{array}$ \\
\hline Environment & R squared \\
predisposing & 0.116 \\
Enabling & 0.134 \\
Need & 0.089 \\
Environment and predisposing & 0.251 \\
Environment and enabling & 0.169 \\
Environment and need & 0.155 \\
Predisposing and enabling & 0.272 \\
Predisposing and need & 0.175 \\
Enabling and need & 0.278 \\
Environment, predisposing and enabling & 0.274 \\
Predisposing, enabling and need & 0.102 \\
Environment, predisposing, enabling and need & 0.300 \\
\hline
\end{tabular}

plained $31.7 \%$ of the variance.

Table 2 presents the unstandardized beta coefficients and significance levels of the variables comprising the environmental, predisposing, enabling, and need clusters. With respect to environmental variables, the more often a person with ID met up with family and friends, the more likely it was that they positively engaged in personal health choices. Regarding predisposing variables, younger age, ratings of poorer health and receiving support from nursing staff in one's home were also more likely to be associated with positive personal health choices. Having a "medical card" i.e., public health insurance that enables no or low cost access to the GP/primary care physician, and receiving support from nurses in one's own home were the enabling variables associated with positive personal health choices. Across the common diseases for adults with ID only reports of stroke and chronic constipation were associated with positive personal health choices in the need grouping. Higher ratings of functional limitations and need for assistance with activities of daily living were similarly associated.

\section{DISCUSSION}

International studies have provided clues that adults with ID, particularly older adults have a greater variety of health care needs compared to those of the same age and gender in the general population $[9,25]$. Many in this study's sample reported experiencing good health but there were significant health concerns with higher incidence of disease and identifiable risk factors for conditions such as coronary artery disease and stroke than for 
Table 2. Unstandardized beta coefficients with p-values derived from hierarchical regression of personal health choices on environmental, predisposing, enabling and need variables.

\begin{tabular}{|c|c|c|}
\hline \multirow{2}{*}{$\begin{array}{l}\text { Independent Variables } \\
\text { Environment }\end{array}$} & \multicolumn{2}{|c|}{ Personal Health Choices } \\
\hline & & p-value \\
\hline Marital status & 0.03 & 0.658 \\
\hline Children & -0.34 & 0.823 \\
\hline Type of Residence & -0.06 & 0.864 \\
\hline Does your residence have a bathroom, bedroom and kitchen all on the same floor or level? & -0.19 & 0.751 \\
\hline $\begin{array}{l}\text { Do you have difficulty getting around inside your home for example, getting to and from the toilet, } \\
\text { going from room to room, such as your bedroom to the living room? }\end{array}$ & 0.63 & 0.151 \\
\hline Summed score of how often you meet up with family and friends & 0.29 & $<0.001$ \\
\hline \multicolumn{3}{|l|}{ Predisposing } \\
\hline Gender & -0.32 & 0.502 \\
\hline Age & -0.1 & $<0.001$ \\
\hline Level of ID & -0.21 & 0.485 \\
\hline Do you have any concerns or worries about getting older? & 1.57 & 0.037 \\
\hline Do you ever feel lonely? & -0.25 & 0.672 \\
\hline Most of the time do you feel happy, not happy or don't know? & 0.45 & 0.123 \\
\hline Would you say your health is excellent, e.g. etc...? & -0.01 & 0.641 \\
\hline \multicolumn{3}{|l|}{ Enabling } \\
\hline Does the lack of transport facilities in your area affect your lifestyle? & -0.32 & 0.502 \\
\hline Medical cover & -0.1 & $<0.001$ \\
\hline Medical insurance & -0.21 & 0.485 \\
\hline Do you receive support from nursing staff in your residence? & 1.57 & 0.037 \\
\hline Do you receive support from other staff (e.g. key worker, support worker) in your residence? & -0.25 & 0.672 \\
\hline Screening score & 0.45 & 0.123 \\
\hline Sum of Q146 and Q147 easy read literature & -0.01 & 0.641 \\
\hline \multicolumn{3}{|l|}{ Need } \\
\hline Heart Condition & -0.28 & 0.696 \\
\hline Has had high blood pressure & -0.16 & 0.811 \\
\hline Has diabetes & 0.3 & 0.729 \\
\hline Has had stroke & 13.15 & $<0.001$ \\
\hline Told has Asthma & 0.4 & 0.691 \\
\hline Told has Chronic constipation & 1.65 & 0.011 \\
\hline Told has Thyroid disease (Hypo/hyperthyroidism) & 0.8 & 0.215 \\
\hline Told has Gastroesophageal reflux disease & -1.03 & 0.224 \\
\hline Told has Osteoporosis/thin or brittle bones & 0.62 & 0.478 \\
\hline Has arthritis (including osteoarthritis or rheumatism) & 0.77 & 0.302 \\
\hline Told has cancer (including leukaemia, lymphoma) & 0.35 & 0.756 \\
\hline Has emotional, nervous or psychiatric condition & 0.35 & 0.464 \\
\hline Has alzheimer's disease & -2.4 & 0.068 \\
\hline Has epilepsy & -0.46 & 0.368 \\
\hline Summed memory score & 0.3 & 0.155 \\
\hline FL SCORE & -0.18 & 0.001 \\
\hline ADL SCORE & -0.28 & 0.01 \\
\hline IADL Score & -0.08 & 0.447 \\
\hline In general, would you consider yourself to be overweight, underweight etc.? & -0.08 & 0.238 \\
\hline
\end{tabular}


same age and older cohorts in the general Irish population. The high prevalence of falls, compared to the general Irish population, was also of concern. Women with ID appeared to be at higher risks for many diseases, both when compared to men with ID and to women in the general population. While health screenings and contacts with GPs/primary care physicians were high, lack of access to some screenings, for example those related to cancers was of concern. Despite apparent good access to health professionals, one in three adults with an ID reported that they found it difficult to make themselves understood when speaking with health professionals which potentially reduces the good effects of such access.

There are also concerns in the data about potential under-reporting of conditions particularly for hypertension, osteoporosis and arthritis. In the Irish adult population there have been recent reports of marked differences between self-report and objectively screened findings for these three conditions [32]. There is no reason not to be concerned that there are similar patterns for people with ID, further highlighting the extent of both actual and potential co-morbid health conditions. The high rates of falls and the low rates of physical activity found here for people with ID may be associated, for example, with under recognized osteoporosis and arthritis. To the extent that these and other conditions are amenable to health promotion and preventative strategies, it becomes all the more important to understand personal health behaviors among people with ID and the factors likely to influence positive personal health behavior practices.

To the extent that the majority of variance in personal health behaviors was driven by need factors, particularly the presence of specific diseases, this suggests that pursuit of positive personal health choices and practices are more likely to be reactive than proactive for people with ID. Taken together with high levels of risk factors for disease such as high cholesterol, high BMI and low levels of physical activity, this finding should be a wake-up call to providers, health professionals, families and people with ID themselves that important opportunities for health promotion are being missed and that prevention is not being emphasized. Given reports of greater likelihood of secondary conditions and that the consequences of additional health concerns as they age often have a greater impact on the independence and quality of life of people with ID [21,22], this is a failing in the health support system that must be better addressed.

Within the data there are indicators of areas where greater success is possible. Positive personal health behaviors were more likely when among environmental factors the individual reported higher levels of social interaction with family and friends. It is of interest that while the literature suggest that where someone lives (residential, community or independently/with family) is important to health and health behaviors [25], it is more likely that the key variable is the extent to which the living environment supports social interaction. This finding is consistent with reports for the general population of the positive effects on health of social support [8] and should encourage providers to facilitate such contacts and families and friends to respond to requests from people with ID for greater interaction.

Among predisposing variables the key factors identified were younger age, ratings of poorer health and concerns about getting older. The finding of younger age is encouraging in that it suggests that adults with ID are open to positive personal health choice messages as well as those who perceive their health as not good and who are becoming concerned about getting older. The challenge for families, health providers and day and residential program staff is to recognize their role in targeting and modeling positive personal health choice messages to these three groups.

Equally, among the enabling variables, the finding that positive personal health choices appear associated with access in the home to nursing staff suggests that this group of health professionals have a particular responsibility to advance positive personal health choices. The Irish ID services system has always featured a cadre of registered nurses in intellectual disability (RNID) embedded within day to day care in residential centers and to some extent in community group homes. This is changing as Ireland seeks to further reduce reliance on large out of home settings [33]. In the midst of a desired increase in community living it will be important to explore how RNIDs will maintain the roles needed to continue and increase their contribution to promoting positive personal health choices.

The finding of having a "medical card" (public health insurance that enables no or low cost access to the GP/ primary care physician) as another important enabling variable taken with the more general finding that the GP/primary care physician was the most frequently accessed health resource points up that the GP/primary care physician also has important role to play. A critical concern is to address reports that one in three adults with an ID reported that they found it difficult to make themselves understood when speaking with health professionals including their GP/primary care physician. Providing easy to read materials targeted at people with ID was rare but even when provided, based upon the regression analysis, did not appear influential in fostering positive personal health choices. Attention is needed to both encouraging GPs/primary care physicians to play a greater role in encouraging positive personal health choices and in developing the tools like to support greater success.

Taken together, the groupings of variables from the 
Anderson Model explained a modest amount of variance in the pursuit of positive personal health choices by people with ID. However, this may reflect there may also be somewhat lower levels of opportunity to influence personal health choices given the low levels of smoking and alcohol consumption as compared to the general population which would restrict the opportunity to measure smoking cessation and alcohol management as personal health choices, something included in many health promotion efforts for the general population. The study is also limited by its self-report nature. Not all variables suggested by Anderson [28] are included (but most are) and there is a paucity of data on effective messages, modeling and programming likely to increase positive personal health choices among this population. More work is clearly needed in developing evidence-based interventions and strategies, and in understanding the relationship between positive personal health choices of people with ID and health outcomes. IDS-TILDA itself will be collecting data over ten years on this identified cohort of individuals and therefore promises to be able to answer at least some of the questions regarding the relationship between personal health choices, pre-existing conditions, onset of new conditions and experience of a quality of life. The data here represent an important baseline understanding and offer guidance for the development of interventions and strategies to improve health outcomes.

\section{REFERENCES}

[1] Janicki, M.P., Dalton, A.J., Henderson, C.M. and Davidson, P.W. (1999) Mortality and morbidity among older adults with intellectual disability: Health services considerations. Disability Rehabilitation, 21, 284-294. doi:10.1080/096382899297710

[2] Janicki, M.P. and Dalton, A.J. (2000) Prevalence of dementia and impact on intellectual disability services. Mental Retardation, 38, 276-288. doi: $10.1352 / 0047-6765(2000) 038<0276$ :PODAIO $>2.0 . \mathrm{C}$ $\underline{\mathrm{O} ; 2}$

[3] Hilgenkamp, T.I.M., Reis, D., van Wijck, R. and Evenhuis, H.M. (2012) Physical activity levels in older adults with intellectual disabilities are low. Research in Developmental Disabilities, 33, 477-483. doi:10.1016/j.ridd.2011.10.011

[4] Reimers, C.D., Knapp, G. and Reimers, A.K. (2012) Does physical activity increase life expectancy? A review of the literature. Journal of Aging Research, 2012, 243958, 9 pages. doi: $10.1155 / 2012 / 243958$

[5] Shikany, J.M. and White Jr., G.L. (2000) Dietary guidelines for chronic disease prevention. Southern Medical Journal, 93, 1138-1151.

[6] Hayes, J.C. (2002) Living arrangements and health status in later life: A review of recent literature. Public Health Nursing, 5, 136-151. doi:10.1046/j.1525-1446.2002.00209.x

[7] Hurdle, D.E. (2001) Social support: A critical factor in women's health and health promotion. Health \& Social Work, 26, 72-79. doi:10.1093/hsw/26.2.72

[8] Uchino, B. (2009). Understanding the links between social support and physical health: A life-span perspective with emphasis on the separability of perceived and received support. Perspectives on Psychological Science, 4, 236-255. doi:10.1111/j.1745-6924.2009.01122.x

[9] US Department of Health and Human Services (2002) Health Centers: America's Primary Care Safety Net Reflections on Success, 2002-2007. US Department of Health and Human Services, Health Resources and Services Administration, Bureau of Primary Health Care, Washington DC.

[10] Haveman, M., Heller, T., Lee, L., Maaskant, M., Shooshtari, S. and Strydom, A. (2010) Major health risks in aging persons with intellectual disabilities: An overview of recent studies. Journal of Policy and Practice in Intellectual Disabilities, 7, 59-69. doi:10.1111/j.1741-1130.2010.00248.x

[11] Van Schrojenstein Lantman De Valk, H.M., Metsemakers, J.F., Haveman, M.J. and Crebolder, H.F. (2000) Health problems in people with intellectual disability in general practice: A comparative study. Family Practice, 17, 405407.

[12] Fletcher, R., Loschen, E., Stavrakaki, C. and First, M. (2007) Diagnostic manual-intellectual disability. NADD and APA, Kingston.

[13] De Winter, C.F., Bastiaanse, L.P., HilgenKamp, T.I.M., Evenhuis, H.M. and Echteld, M.A. (2012) Overweight and obesity in older people with intellectual disability. Research in Developmental Disabilities, 33, 398-405. doi:10.1016/j.ridd.2011.09.022

[14] McCarron, M., Swinburne, J., Burke, E., McGlinchey, E., Mulryan, N., Andrews, V., Foran S. and McCallion, P. (2011) Growing older with an intellectual disability in Ireland 2011: First results from the intellectual disability supplement of the Irish longitudinal study on ageing. School of Nursing \& Midwifery, Trinity College, Dublin.

[15] Evenhuis, H.M., Theunissen, M., Denkers, I., Verschuure, H. and Kemme H. (2001) Prevalence of visual and hearing impairment in a Dutch institutionalized population with intellectual disability. Journal Intellectual Disability Research, 45, 457-464. doi:10.1046/j.1365-2788.2001.00350.x

[16] WHO (2001) International classification of functioning, disability and health. World Health Organization, Geneva.

[17] Cooper, S.A., Melville, C. and Morrison J. (2004) People with intellectual disabilities. Their health needs differ and need to be recognized and met. British Medical Journal, 329, 414-415. doi:10.1136/bmj.329.7463.414

[18] Strauss, D., Kastner, T.A. and Shavelle, R. (1998) Mortality of adults with developmental disabilities living in California institutions and community care, 1985-1994. Mental Retardation, 36, 360-371. doi:10.1352/0047-6765(1998)036<0360:MOAWDD>2.0. $\underline{\mathrm{CO} ; 2}$

[19] McCarron, M. and Lawlor, B. (2003) Responding to the 
challenges of ageing and dementia in intellectual disability in Ireland. Aging and Mental Health, 7, 413-417. doi:10.1080/13607860310001594655

[20] Iacono, T. and Sutherland, G. (2006) Health screening and developmental disability. Journal of Policy and Practice in Intellectual Disability, 3, 155-163. doi:10.1111/j.1741-1130.2006.00075.x

[21] Suzuki, R., Krahn, G.L., McCarthy, M.J. and Adams, E.J. (2007) Understanding health outcomes: Physical seconddary conditions in people with spinal cord injury. Rehabilitation Psychology, 52, 338-350. doi:10.1037/0090-5550.52.3.338

[22] Rimmer, J.H., Chen, M.-D. and Hsieh, K. (2011) A conceptual model for identifying, preventing and managing secondary conditions in people with disabilities. Physical Therapy, 91, 1728-1739. doi:10.2522/ptj.20100410

[23] Hughes, R.B. (2006) Achieving effective health promotion for women with disabilities. Family Community Health, 29, 44S-51S. doi:10.1097/00003727-200601001-00008

[24] Rimmer, J.H. and Rowland, J.L. (2008) Health promotion for people with disabilities. American Journal of Lifestyle Medicine, 10, 1-12.

[25] Haveman, M., Heller, T., Maaskant, M., Lee, L., Shooshtari, S. and Strydom, A. (2009) Health risks in older adults with intellectual disabilities: A review of studies (IASSID report). http://www.IASSID.org

[26] Cooper, S.A., Morrison, J., Melville, C., Finlayson, J., Allan, L., Martin, G. and Robinson, N. (2006) Improving the health of people with intellectual disabilities: Out- comes of a health screening programme after 1 year. Journal of Intellectual Disability Research, 50, 667-677. doi:10.1111/j.1365-2788.2006.00824.x

[27] Lennox, N., Bain, C., Rey-Conde, T., Purdie, D., Bush, R., and Pandeya, N. (2007) Effects of a comprehensive health assessment programme for Australian adults with intellectual disability: A cluster randomized trial. International Journal of Epidemiology, 36, 139-146. doi:10.1093/ije/dyl254

[28] Anderson, R.M. (1995) Revisiting the behavioral model and access to medical care: Does it matter? Journal of Health and Social Behavior, 36, 1-10. doi: $10.2307 / 2137284$

[29] Kelly, C. and Kelly, F. (2011) Annual Report of the National Intellectual Disability Database Committee. Health Research Board, Dublin.

[30] Green, S.B. (1991) How many subjects does it take to do a regression analysis? Multivariate Behavioral Research, 26, 499-510. doi:10.1207/s15327906mbr2603 7

[31] Albert, M. and Cohen, C. (1992) The test for severe impairment. Journal of American Geriatric Society, 40, 449453.

[32] Barrett, A., Savva, G., Timonen, V. and Kenny, R.A. (2011) Fifty Plus in Ireland 2011, First Results from the Irish Longitudinal Study on Ageing. Trinity College, Dublin.

[33] HSE (2011) Time to Move on from Congregated Settings: A Strategy for Community Inclusion Report of the Working Group on Congregated Settings. Health Service Executive, Dublin. 